\title{
A Longitudinal Daily Diary Study of Family Assistance and Academic Achievement Among Adolescents from Mexican, Chinese, and European Backgrounds
}

\author{
Eva H. Telzer · Andrew J. Fuligni
}

Received: 3 November 2008/Accepted: 29 December 2008/Published online: 10 January 2009

(C) The Author(s) 2009. This article is published with open access at Springerlink.com

\begin{abstract}
A longitudinal daily diary method was employed to examine the implications of family assistance for the academic achievement of 563 adolescents (53\% female) from Mexican $(n=217)$, Chinese $(n=206)$, and European $(n=140)$ backgrounds during the high school years (mean age 14.9 years in 9 th grade to 17.8 years in 12 th grade). Although changes in family assistance time within individual adolescents were not associated with simultaneous changes in their Grade Point Averages (GPAs), increases in the proportion of days spent helping the family were linked to declines in the GPAs of students from Mexican and Chinese backgrounds. The negative implications of spending more days helping the family among these two groups was not explained by family background factors or changes in study time or school problems. These results suggest that the chronicity rather than the amount of family assistance may be difficult for adolescents from Mexican and Chinese backgrounds.
\end{abstract}

Keywords Family assistance - Academic achievement . Ethnically diverse adolescents

E. H. Telzer $(\bowtie)$

Department of Psychology, University of California,

1285, Franz Hall, Los Angeles, CA 90095-1563, USA

e-mail: ehtelzer@ucla.edu

\section{A. J. Fuligni}

Center for Culture and Health, Semel Institute for Neuroscience and Human Behavior, University of California, Los Angeles, CA, USA

e-mail: afuligni@ucla.edu

\section{Introduction}

Youth from Latin American and Asian backgrounds place a strong emphasis on family obligation and assistance (Fuligni et al. 1999; Hardway and Fuligni 2006). Although teenagers from these families believe that trying hard and doing well in school is one of their primary family obligations (Suarez-Orozco and Suarez-Orozco 1995), the very real need to provide assistance to the family on a daily basis could potentially interfere with their academic achievement by reducing the time available for studying, compromising their ability to complete homework successfully, and making it difficult to make it to school and attend classes on time. Little is known, however, about how actual family assistance, such as sibling care and housework, is associated with academic performance at school. Although some theorists suggest that family assistance may impede achievement (e.g., Chase 1999), this link has not been systematically tested among adolescents from a variety of backgrounds. The current study used a longitudinal daily diary method in order to examine the implications of family assistance behaviors for the academic achievement of adolescents from Mexican, Chinese, and European backgrounds during the high school years.

\section{Family Assistance and Academic Achievement}

Family assistance is an important feature of adolescent daily life and provides a sense of meaning and connection to the family. Youth from diverse backgrounds engage in family assistance behaviors on a daily basis by caring for siblings, doing household chores, and helping their parents (Hardway and Fuligni 2006). Family assistance is a particularly important aspect of family life for youth from Latin American and Asian backgrounds, especially for 
those from immigrant families (Fuligni et al. 1999; Hardway and Fuligni 2006; Orellana 2001; Suarez-Orozco and Suarez-Orozco 1995). These adolescents spend significantly more time assisting their family and value it more so than their peers from European backgrounds (Fuligni and Pederson 2002; Fuligni et al. 1999; Hardway and Fuligni 2006)

In addition, adolescents from Latin American and Asian backgrounds often feel that trying hard in school is an obligation to their family, and they believe in the usefulness of education for both themselves and their family (Fuligni 1997; Suarez-Orozco and Suarez-Orozco 1995; Suarez-Orozco 1991). Adolescents from immigrant families often believe that they can repay their parents for the sacrifices they made in coming to the United States by succeeding in school (Suarez-Orozco and Suarez-Orozco 1995). Youth who believe they should support, assist, and respect their family place a stronger value on academic achievement and going to college (Fuligni 2001). Furthermore, although academic motivation rapidly decreases with the transition to high school, this decline is substantially smaller for adolescents with a strong sense of family obligation (Fuligni 2001). Nonetheless, despite their high academic motivation, adolescents with the strongest sense of family obligation receive grades that are similar to or lower than their peers who value family obligation the least (Fuligni et al. 1999). One reason for this may be that adolescents who value family obligation the most are more likely to engage in actual family assistance behaviors on a daily basis (Hardway and Fuligni 2006), which may make it difficult for them to achieve in schools at levels equivalent to their motivation.

Family assistance behaviors have rarely been examined even though they occur within most families, on a frequent basis, and in many different domains. For example, youth from immigrant families often act as interpreters for their parents and help with the translation of official documents (Buriel et al. 1998; Orellana et al. 2003). Similarly, adolescents from Latin American and Asian backgrounds spend a significant amount of time caring for their siblings and doing household chores such as cooking and cleaning (Fuligni et al. 1999; Hardway and Fuligni 2006). In addition, youth from economically disadvantaged households often help manage their families' finances, take on a job, or work for the family business in order to contribute to the financial needs of their family (Burton 2007). Thus, family assistance likely plays a key role in adolescents' development, and the demands associated with these family assistance behaviors may detract from youths' study time and make it difficult for them to effectively manage their time between school and family work.

Because of the demands associated with helping the family, family assistance behaviors may negatively impact youths' academic achievement. Some researchers argue that assisting the family may be stressful and interfere with school work, particularly by reducing adolescents' study time (Chase 1999). Indeed, ethnographic work has shown that adolescents from immigrant families often report a sense of conflict and feel torn between doing their school work and assisting their family (Suarez-Orozco and Suarez-Orozco 1995; Suarez-Orozco 1991). Further, immigrant college students who assist their family more receive lower grades despite their increased academic motivation (Tseng 2004). In addition, young adults who provide financial support to their family are less likely to pursue postsecondary school, and those who live with their parents receive lower grades (Fuligni and Witkow 2004). Finally, youth who engage in very high levels of family assistance within economically disadvantaged families often miss school and have a diminished attachment to school (Burton 2007). Thus, for some youth, assisting the family may be stressful and hard to manage detracting from their ability to succeed in school.

\section{Group Differences in the Implications of Family}

Assistance for Achievement

Family assistance may be more consequential for Mexican and Chinese adolescents, because they take on more household responsibilities than their European peers. In addition, because family obligation is more important to them, Mexican and Chinese adolescents may experience feelings of conflict deriving from the need to balance their time between school work and family obligations (SuarezOrozco and Suarez-Orozco 1995). Finally, because they are likely to put the needs of their family before their own needs, Mexican and Chinese youth may sacrifice their school work in order to assist their family. Similar characterizations have been made about gender differences in family assistance, with family assistance being described as more important and consequential for girls than boys (Crouter et al. 2001).

Ethnic differences observed in family assistance and academic achievement may be attributable to the immigrant status of the Mexican and Chinese youth. Adolescents from immigrant backgrounds may show a stronger negative association between family assistance and achievement due to stresses that are unique to immigrants. Language barriers for the adolescent or parents may make the educational process especially stressful. For example, having not attended American schools immigrant parents may feel disconnected from their child's education, perhaps unable to communicate with teachers and get fully involved in their child's education (Birman 2006). Further, the need to translate for their parents may add an extra stress on an immigrant child's family obligations. Immigrant youth 
often feel that they can help their families' acculturation by becoming cultural brokers for their parents and aiding them in issues related to school, employment and official business (Valenzuela 1998).

Finally, any observed ethnic differences may also be accounted for by socioeconomic status and family composition differences. Mexican and Chinese adolescents' parents, especially immigrants, usually have lower status occupations, less education, and these youth often have more family members living in residence, including grandparents and siblings, compared to their European peers (Hardway and Fuligni 2006). Family assistance within families characterized by stress or economic strain has been associated with more school problems in recent ethnographies (e.g., Burton 2007). Thus, youth who come from single-parent households, have large numbers of siblings, or have parents with lower status occupations and less education may experience more strain from their family assistance because it is taking place within more difficult family environments.

\section{Potential Mediators of the Links Between Assistance and Achievement}

One reason family assistance may lead to lower academic achievement is because assisting the family interferes with adolescents' study time. Many researchers and ethnographers suggest that spending more time helping the family may detract from adolescents' ability to concentrate on school work and spend time studying (Chase 1999; Suarez-Orozco and Suarez-Orozco 1995; Tseng 2004). Interviews with immigrant youth suggests that they feel conflicted about spending time on their homework when they have duties to assist their family (Suarez-Orozco and Suarez-Orozco 1995). A second reason that family assistance may impede achievement is because it causes school problems. Youth who experience family stresses, such as conflict with parents and family demands, show increased learning and attendance problems at school (Flook and Fuligni 2008). Thus, the demands associated with family assistance may prevent youth from completing their homework successfully and may cause them to be late to school, have trouble turning assignments in on time, or do poorly on a test or quiz.

\section{The Current Study}

The present study used a longitudinal daily diary method to examine the association between daily family assistance and the academic achievement of Mexican, Chinese, and European adolescents. We examined ethnic, gender, generational, socioeconomic status, and family composition differences in the association between daily family assistance and achievement throughout the high school years. Examining the daily lives of youth over several years will help us to understand how family assistance functions in these youths' lives. By employing a longitudinal study, we can examine how changes in family assistance over time are simultaneously associated with changes in academic achievement within individual adolescents. Such withinperson longitudinal analyses provide us with more confidence that changes in achievement are accounted for by family assistance itself and not to other unmeasured individual characteristics of the adolescent. In addition, daily reporting of family assistance provides more valid and reliable estimates of adolescents' daily behaviors than traditional retrospective reporting because daily reports capture life as it is lived (Bolger et al. 2003).

We examined whether assisting the family impedes achievement by examining both the amount of time and the number of days that adolescents spend helping their family. Family assistance time represents the average amount of time adolescents spend helping their family over the 2 week daily diary period whereas family assistance days represents the proportion of days that adolescents spend helping their family. Adolescents who spend the same amount of time on average helping their family may distribute that time differently across the days of the week. Some adolescents may not help every day and instead help a lot on the weekends and perhaps little to none on the weekdays, thereby enabling them to focus on studying during school days. In contrast, adolescents who spend a large proportion of days helping their family may not be able to manage their time as effectively and may have to multitask in order to complete their family obligations and school work. Irrespective of the amount of time spent helping, spending a significant proportion of days assisting the family suggests that it is a chronic behavior in adolescents' lives that may interfere with studying and focusing on school demands.

\section{Research Questions and Hypotheses}

We sought to answer three key questions in the current study. First, does family assistance relate to academic achievement over time within adolescents from Mexican, Chinese, and European backgrounds? We expected that family assistance may be more consequential for youth from Mexican and Chinese backgrounds because they take on more household chores, and, given their high levels of family obligation values, they may also sacrifice their school work more in order to help their family.

Second, we examined whether any observed ethnic differences in the associations between family assistance and achievement are due to generational status, socioeconomic 
background, or family composition. Adolescents from Chinese and Mexican backgrounds are more likely to come from immigrant families and from households of lower socioeconomic status and with more family members in residence. We expected that family assistance may impede achievement when it takes place within difficult home environments such as those with lower socioeconomic status, more siblings in residence, single-parents, or immigrant parents who may depend more on their children to help.

Third, do studying and school problems mediate any observed association between family assistance and academic achievement? We predicted that family assistance may affect achievement because it detracts from adolescents' ability to effectively study and complete their homework and may cause problems such as being late for school, skipping classes, or doing poorly on an assignment. Therefore, we examined whether family assistance compromised academic achievement because of its impact on studying and school related problems.

\section{Method}

\section{Sample}

Ninth grade students were recruited from three public high schools in the Los Angeles metropolitan area to participate in a longitudinal study. The ethnic composition, overall level of achievement, and socioeconomic backgrounds of the participants reflected those of the communities from which the students were drawn. The first school was populated predominantly by students from Latin American and Asian backgrounds who came from lower-middle to middle class families and tended to be in the lower-middle to middle range of the achievement distribution of schools in California (California Department of Education 2006). Over $50 \%$ of students received free and reduced meals, and over $10 \%$ qualified for California Work Opportunity and Responsibility to Kids (CalWorks), a welfare program in California that provides cash aid and services to eligible families (California Department of Education 2006). The second school tended to have average achievement levels and enrolled students of predominantly Latin American and European backgrounds from lower-middle to middle class families. Less than $20 \%$ of students qualified for free or reduced-priced meals and less than $5 \%$ were eligible for CalWORKS. Finally, the third school enrolled students from mostly Asian and European backgrounds whose families tended to be middle to upper-middle class. The achievement levels at this school tended to be above average (California Department of Education 2006). Less than $10 \%$ of students qualified for free or reduced-priced meals and $<1 \%$ qualified for CalWORKS. No single ethnic group dominated any of the schools. Rather, the two most common ethnic groups each comprised approximately $30-50 \%$ of the total population of each school (California Department of Education 2006).

Students were followed in the 9th, 10th, and 12th grades. In two of the schools, the entire ninth grade was invited to participate during the first year of the study, and in subsequent years all students in the correct grade were invited to participate. Each year, approximately $60 \%$ of the enrolled students in the appropriate grade levels participated in the study. In the third school, half of the students in the ninth grade were invited to participate because of the large size of the school and approximately $50 \%$ of the invited students participated each year. In this school, only students who had participated in the ninth grade were followed in subsequent years. Students who had participated in earlier years but were no longer enrolled in their original school were contacted by mail and invited to participate in the following years.

The sample used in the current study is the 563 participants from Mexican $(n=217)$, Chinese $(n=206)$, and European $(n=140)$ backgrounds who completed daily diaries for at least two of the 3 years of the study. The mean ages of the students ranged from 14.86 years $(\mathrm{SD}=0.37)$ in the 9 th grade to 17.80 years $(\mathrm{SD}=0.36)$ in the 12th grade. The sample was evenly divided between males $(47 \%)$ and females (53\%). Most of the students from Mexican and Chinese backgrounds were from immigrant families: $15.2 \%$ of Mexican and 29.6\% of Chinese adolescents were first generation (youth were born outside of the United States) and 55.3 and $64.6 \%$, respectively were second generation (youth were born in the United States, but at least one parent was foreign born). Those from European backgrounds were predominantly of the third generation or greater $(68.6 \%$; youth and both of their parents were born in the United States).

As shown in Table 1, parents of students with European backgrounds were more likely to have received college degrees than parents of students with Chinese backgrounds, who, in turn, were more likely to have at least attended college than the parents of students with Mexican backgrounds, $F(2,540)=77.23, p<.001 ; \eta^{2}=.22$. Ethnic differences in occupational status followed a similar pattern, with parents of students from European backgrounds being employed in higher level occupations than Chinese parents, who, in turn, worked in higher status occupations than Mexican parents, $F(2,528)=62.78, p<.001 ; \eta^{2}=.19$. Adolescents also differed in family composition variables, with Chinese parents being more likely to be married than parents of students from Mexican or European backgrounds, $F(2,560)=12.46, p<.001 ; \eta^{2}=.04$. In addition, adolescents from Chinese backgrounds were more likely to have grandparents living in residence than adolescents from 
Table 1 Socioeconomic background and family composition according to ethnic group

\begin{tabular}{|c|c|c|c|}
\hline Variable & Mexican & Chinese & European \\
\hline \multicolumn{4}{|l|}{ Mother's education } \\
\hline Did not complete high school & $39.6 \%$ & $33.3 \%$ & $2.1 \%$ \\
\hline Completed high school & $24.5 \%$ & $20.2 \%$ & $10.7 \%$ \\
\hline Completed some college & $23.1 \%$ & $12.8 \%$ & $25.7 \%$ \\
\hline Completed 4-year college & $12.7 \%$ & $33.5 \%$ & $61.4 \%$ \\
\hline \multicolumn{4}{|l|}{ Father's education } \\
\hline Did not complete high school & $41.4 \%$ & $28.8 \%$ & $6.1 \%$ \\
\hline Completed high school & $22.7 \%$ & $19.0 \%$ & $10.6 \%$ \\
\hline Completed some college & $17.2 \%$ & $10.9 \%$ & $19.7 \%$ \\
\hline Completed 4-year college & $18.7 \%$ & $41.3 \%$ & $63.6 \%$ \\
\hline \multicolumn{4}{|l|}{ Parental employment } \\
\hline $\begin{array}{l}\text { Mother employed } \\
\quad \text { (all } 3 \text { years of study) }\end{array}$ & $59.4 \%$ & $55.5 \%$ & $73.6 \%$ \\
\hline $\begin{array}{l}\text { Father employed } \\
\quad \text { (all } 3 \text { years of study) }\end{array}$ & $76.5 \%$ & $72.3 \%$ & $80.7 \%$ \\
\hline $\begin{array}{l}\text { Mother employed in } \\
\text { semiprofessional or } \\
\text { professional occupation }\end{array}$ & $20.2 \%$ & $40.3 \%$ & $70.0 \%$ \\
\hline $\begin{array}{l}\text { Father employed in } \\
\text { semiprofessional or } \\
\text { professional occupation }\end{array}$ & $20.3 \%$ & $45.3 \%$ & $72.3 \%$ \\
\hline \multicolumn{4}{|l|}{ Family composition } \\
\hline Parents married & $60.8 \%$ & $76.7 \%$ & $52.1 \%$ \\
\hline Two parents in residence & $78.7 \%$ & $83.9 \%$ & $77.0 \%$ \\
\hline Number of siblings in residence & 1.64 & 1.25 & 0.92 \\
\hline Grandparent(s) in residence & $14.7 \%$ & $26.7 \%$ & $8.6 \%$ \\
\hline
\end{tabular}

Note: Semiprofessional occupation status included such occupations as nurse and office manager, and professional occupations included occupations such as architect and physician

Mexican or European backgrounds, $F(2,560)=10.78$, $p<.001 ; \eta^{2}=.04$, and adolescents from Mexican backgrounds lived with more siblings than adolescents from Chinese backgrounds, who, in turn, lived with more siblings than adolescents from European backgrounds, $F(2,560)=$ $22.81, p<.001 ; \eta^{2}=.06$. The likelihood of having two parents in residence did not differ by ethnicity, $F(2,533)=$ $1.43, n s$.

\section{Procedure}

Students who returned parental consent forms and provided their own assent to participate completed an initial questionnaire during class time, a brief demographic questionnaire at home, and 14 days of diary checklists every night before going to bed for two subsequent weeks. The three page diary checklists took approximately $5-10 \mathrm{~min}$ to complete each night. Participants were called once per week during the 2 week period in order to remind them to complete the diary checklists and to answer any of their questions. Participants were instructed to put their completed diary checklists into a sealed envelope each night and to stamp the seal of the envelope with an electronic time stamper. The time stamper imprinted the current date and time and was programmed with a security code such that adolescents could not alter the correct time and date. At the end of the 2 week period, participants returned the materials to the school and received $\$ 30$ for participating. In addition, the students were told that they would receive two movie passes if inspection of the data indicated that they had completed the diaries correctly. This method of monitoring resulted in a high rate of compliance, with $97.5-98.5 \%$ of the dairies being completed each year.

Measures

Participants completed the following measures during each year of the study. All study materials were available in English, Chinese, and Spanish, and only one student chose to complete the questionnaire in Spanish in the ninth grade. All students completed the study materials in English in subsequent years.

\section{Daily Diary Measures}

\section{Daily Family Assistance}

Each evening for 14 days, adolescents indicated whether they had engaged in any of the following eight activities: helped clean the apartment or house, took care of siblings, ran an errand for the family, helped siblings with their schoolwork, helped parents with official business, helped to cook a meal for the family, helped parents at their work, and other. Participants then estimated the total amount of time they had spent in all of the activities that day. Focus group studies with adolescents helped to inform the development of this list of activities and it has been used successfully in previous studies with these populations (e.g., Fuligni et al. 2002; Hardway and Fuligni 2006).

The following measures were created from these reports by taking the daily averages over 14 days: assistance days, which represented the proportion of days out of 14 days the participant assisted the family in any one of the eight activities; and assistance time, which represented the average number of hours spent helping the family each day over 14 days.

\section{Daily Studying}

Each evening for the 2 week period, adolescents estimated the total time they spent studying outside of school. The following measures were created from these reports by 
taking the daily averages over 14 days: study days, which represented the proportion of days out of 14 days the participant studied; and study time, which represented the average number of hours spent studying each day over 14 days.

\section{Daily School Problems}

Participants indicated any problems related to learning and attendance at school for 2 weeks. Each day, adolescents indicated whether they had experienced any of the following three learning problems: did not understand something taught in class, did poorly on a test, quiz, or homework, and did not turn in homework that was due; and any of the following four attendance problems: had difficulty getting to school on time, were late for class, skipped or cut a class, and skipped school. Total school problems were summed each day and averaged over the 2 week period to create two indices, learning problems and attendance problems.

\section{Questionnaire Measures}

\section{Parental Education and Occupation}

Participants reported their mother's and father's highest level of education by responding to a scale that ranged from "elementary/junior high school," "some high school," "graduated from high school," "some college," "graduated from college," to "law, medical, or graduate school." Participants also indicated their parents' occupational status. Occupation was coded on a five point scale $(1=$ unskilled level to $5=$ professional level $)$ that has been used in previous studies with a similar population (Fuligni 1997, 1998). Examples of unskilled worker included furniture mover, gas station attendant, food service worker, and housecleaner; semiskilled worker included baker, cashier, landscaper, and security guard; skilled worker included appraiser, barber, seamstress, and electrician; semiprofessional worker included nurse, librarian, optometrist, and office manager; and professional worker included architect, dentist, computer consultant, and physician. Occupational status was not coded if the participant indicated a parent was unemployed.

\section{Family Composition}

Adolescents indicated the total number of siblings that were living in their home and whether they lived with their grandparents. In addition, participants indicated which parents they lived with, including step parents. A measure was created to represent whether the adolescent lived in a dual parent household. An adolescent who resided with two or more parents (including step parents) was coded as living in a dual parent household whereas those who reported living with just one parent were coded as living in a single parent household.

\section{Grade Point Average (GPA)}

Adolescents' course grades were obtained from official school records at the end of the school year. Grades were averaged to create an index of academic performance, where $0=F, 1=D, 2=C, 3=B$, and $4=A$. Adolescents took the same social studies classes and generally took the same levels of English and science classes (65-75\% took the same level courses). Although the levels of adolescents' mathematics classes varied, we did not standardize grades within levels of mathematics classes because students in higher level classes generally earned higher grades than those in lower level classes.

\section{Results}

\section{Participation Analyses}

Initial analyses were conducted to examine differences between adolescents according to their degree of participation in the study. The sample included adolescents who participated in at least 2 years of the study and most participated in all 3 years $(M=2.69$ years, $\mathrm{SD}=.46)$. Participants entered the study at different years, therefore an adolescent who began the study in the ninth grade had three possible years to participate whereas an adolescent who began the study in the tenth grade had only two possible years to participate. A variable was created to indicate the percentage of possible years each adolescent participated in the study. Overall, participants took part in the study in $94 \%(\mathrm{SD}=13 \%)$ of their possible years. Differences were found in the degree of participation as a function of gender and ethnicity such that females $(M=94.8 \%, \mathrm{SD}=12 \%)$ participated in more years than males $(M=92.4 \%, \mathrm{SD}=14 \% ; t(559)=2.23, p<.05)$, and adolescents from Chinese backgrounds participated in more years $(M=95.7 \%, \mathrm{SD}=11 \%)$ than adolescents from European backgrounds $(M=92 \%, \mathrm{SD}=14 \%)$, $F(2,560)=4.10, p<.05$. There were no differences in the degree of participation as a function of generation.

Next, we examined whether there were differences in any of the time varying variables (i.e., GPA, family assistance, studying, and school problems) as a function of participation. Hierarchical Linear Models (HLM; Bryk and Raudenbusch 1992) were estimated using the following equations: 
GPA, Assistance days, etc ${ }_{\cdot i j}=b_{0 j}+e_{i j}$

$b_{0 j}=c_{00}+c_{01}($ Participation $)+u_{0 j}$

Equation 1 represents adolescents' scores on the time varying variables (i.e., GPA, family assistance, studying, and school problems) across the years of their participation in the study, and Eq. 2 represents the prediction of the adolescents' average scores across their years of participation as a function of their degree of participation (the percent of possible years that they took part in the study). Adolescents who participated in more years of the study had higher GPAs $(b=1.33, p<.001)$, fewer assistance days $(b=-.17, p<.05)$, greater study time $(b=.94$, $p<.01)$, and fewer learning $(b=-2.30, p=.05)$ and attendance $(b=-3.96, p<.001)$ problems at school. There were no differences in assistance time and study days based on degree of participation.

\section{Overall Ethnic and Gender Differences in Average Family Assistance and GPA}

In order to provide an initial portrait of the overall rates of family assistance and academic achievement, we examined whether there were ethnic or gender differences in average levels of family assistance and GPA across the 4 years of high school. Separate models were analyzed for GPA and the two indices of family assistance (time and days). The statistical model that was estimated was as follows:

$$
\begin{aligned}
& \text { GPA or Family assistance } i j=b_{0 j}+e_{i j} \\
& \begin{aligned}
b_{0 j}= & \left.c_{00}+c_{01}(\text { Gender })+c_{02} \text { (Mexican }\right) \\
& +c_{03}(\text { Chinese })+u_{0 j}
\end{aligned}
\end{aligned}
$$

Equation 3 represents adolescents' GPA or family assistance on a particular year $(i)$ for a particular individual $(j)$ modeled as a function of the average GPA or family assistance of the individual $\left(b_{0 j}\right)$. Equation 4 shows how the average GPA or family assistance was modeled as a function of the adolescents' gender and ethnicity. Gender was coded as males $=0$ and females $=1$, and Chinese and Mexican were dummy coded as $0=$ not Chinese or not Mexican, and $1=$ Chinese or Mexican, respectively. The ethnicity coding resulted in adolescents with European backgrounds being the baseline group.

As shown in Table 2, adolescents from Chinese and Mexican backgrounds spent more time on average over the high school years helping their family than youth from European backgrounds, and females spent more time on average helping than males. In contrast, only youth from Mexican backgrounds spent more days on average helping their family compared to their European peers, whereas adolescents from Chinese and European backgrounds and males and females did not differ in the proportion of days
Table 2 Hierarchical linear modeling predicting average GPA, assistance days, and assistance time across the high school years by ethnicity and gender

\begin{tabular}{cllr}
\hline & $\begin{array}{l}\text { Assistance time } \\
b(\mathrm{SE})\end{array}$ & $\begin{array}{l}\text { Assistance days } \\
b(\mathrm{SE})\end{array}$ & \multicolumn{1}{l}{$\begin{array}{l}\text { GPA } \\
b(\mathrm{SE})\end{array}$} \\
\hline Intercept & $.58(.06)^{* * *}$ & $.58(.02)^{* * *}$ & $2.97(.06)^{* * *}$ \\
Gender & $.14(.07)^{*}$ & $.01(.02)$ & $.19(.05)^{* * *}$ \\
Mexican & $.66(.08)^{* * *}$ & $.19(.03)^{* * *}$ & $-.60(.07)^{* * *}$ \\
Chinese & $.21(.08)^{* *}$ & $.04(.03)$ & $.12(.06)^{*}$ \\
\hline
\end{tabular}

Note: Assistance days represents the proportion of days adolescents helped their family by engaging in one or more of the eight family assistance behaviors. Assistance time represents the average time adolescents spent helping their family. Gender was coded males $=0$, females $=1$. Ethnicity was dummy coded with adolescents from European backgrounds serving as the reference group. $* p<.05$, $* * p<.01, * * * p<.001$

they spent helping their family on average. In terms of achievement, youth from Mexican backgrounds attained lower grades on average over the high school years compared to adolescents from European backgrounds, whereas adolescents from Chinese backgrounds achieved at higher levels than their European peers. Finally, females attained higher grades on average than males.

Ethnic and Gender Differences in Family Assistance Predicting GPA

Next, we examined our first key research question, which focused on the association between family assistance and GPA across time within adolescents and whether that association varied according to gender and ethnic background. The statistical model that was estimated was as follows:

$$
\begin{aligned}
& \mathrm{GPA}_{i j}=b_{0 j}+b_{1 j}(\text { Family assistance })+e_{i j} \\
& b_{0 j}=c_{00}+c_{01}(\text { Gender })+c_{02}(\text { Mexican }) \\
&+c_{03}(\text { Chinese })+u_{0 j} \\
& b_{1 j}=c_{10}+c_{11}(\text { Gender })+c_{12}(\text { Mexican }) \\
&+c_{13}(\text { Chinese })+u_{1 j}
\end{aligned}
$$

Equation 5 represents adolescents' GPA on a particular year $(i)$ for a particular individual $(j)$ modeled as a function of the average GPA of the individual $\left(b_{0 j}\right)$ and their family assistance $\left(b_{1 j}\right)$. Assistance time and assistance days were each estimated separately. Additional analyses controlling for year of high school (i.e., 9th, 10th, and 12th grade) yielded similar results, so the results without that control are presented for the sake of simplicity.

Equations 6 and 7 show how both the average GPA and the effect of family assistance were modeled as a function 
Table 3 Hierarchical linear modeling predicting GPA by family assistance time and days

\begin{tabular}{lcl}
\hline & \multicolumn{2}{l}{ GPA } \\
\cline { 2 - 3 } & $\begin{array}{l}\text { Assistance time } \\
b(\mathrm{SE})\end{array}$ & $\begin{array}{l}\text { Assistance days } \\
b(\mathrm{SE})\end{array}$ \\
\hline Intercept & $3.05(.07)^{* * *}$ & $2.97(.08)^{* * *}$ \\
Gender & $.19(.06)^{* *}$ & $.15(.08)^{*}$ \\
Mexican & $-.57(.08)^{* * *}$ & $-.30(.12)^{* *}$ \\
Chinese & $.06(.07)$ & $.23(.09)^{* *}$ \\
Family assistance & $-.06(.05)$ & $.07(.11)$ \\
Gender & $-.01(.04)$ & $.04(.10)$ \\
Mexican & $.01(.05)$ & $-.43(.14)^{* *}$ \\
Chinese & $.05(.05)$ & $-.23(.12)^{*}$ \\
Standard deviation & .08 & .17 \\
of assistance estimate & & \\
\hline
\end{tabular}

Note: The two columns show results for the prediction of GPA by assistance time and days, respectively. Assistance days represents the proportion of days adolescents helped their family by engaging in one or more of the eight family assistance behaviors. Assistance time represents the average time adolescents spent helping their family. Gender was coded males $=0$, females $=1$. Ethnicity was dummy coded with adolescents from European backgrounds serving as the reference group. $* p<.05, * * p<.01, * * * p<.001$

of the adolescents' gender and ethnicity. Gender was coded as males $=0$ and females $=1$, and Chinese and Mexican were dummy coded as $0=$ not Chinese or not Mexican, and $1=$ Chinese or Mexican, respectively. The ethnicity coding resulted in adolescents with European backgrounds being the baseline group.

As shown in Table 3, changes in time spent helping the family were unassociated with changes in GPA within individual adolescents, and there were no differences in this association by ethnicity or gender. Further, estimates of the degree of individual variability in the association between family assistance time and GPA was non-significant, suggesting that the implications of assistance time for GPA are generally similar across adolescents. In contrast, there were ethnic differences in the association between assistance days and achievement. Although changes in assistance days were not associated with changes in GPA for adolescents from European backgrounds, who were the baseline group, there was a negative association between assistance days and GPA among adolescents with Mexican and Chinese backgrounds. These results indicate that as adolescents from Mexican and Chinese backgrounds increased their assistance days across the high school years, their GPAs simultaneously declined. The individual variability in the association between assistance days and GPA was non-significant, suggesting that there was no additional significant variability in the implications of assistance days for GPA after accounting for ethnicity and gender.
Generation, Socioeconomic Status, and Family Composition

Additional HLM models were analyzed in order to examine whether the significant ethnic differences reported in Table 3 could be accounted for by generation, socioeconomic status, and family composition differences. The indices of generation, socioeconomic status (mean of parental education and occupation), and family composition (living with two parents, having grandparents in residence, and number of siblings in residence) were added to Eqs. 6 and 7. Results indicated, however, that none of these indices were significant predictors of the withinperson association between family assistance and GPA, and the significant ethnic differences in the association between assistance days and achievement remained after accounting for generational, socioeconomic, and family composition differences.

Mediating Family Assistance and GPA with Studying and School Problems

Given the link between assistance days and achievement within adolescents from Chinese and Mexican backgrounds, we estimated additional HLM models to determine whether these within-person associations were mediated by the amount of studying adolescents did and whether they experienced school problems. We first examined whether family assistance days was associated with studying and school problems. Four separate HLM models were run with the same equations as those used in Eqs. 5, 6 and 7, but this time with study days, study time, learning problems, and attendance problems as the outcome variables. As shown in the first column of Table 4, changes in assistance days were not associated with changes in study time within adolescents, and there were no ethnic differences in this association. In contrast, there was a positive association between assistance days and study days such that increases in the days spent helping the family was associated with increases in the days spent studying, and this association did not vary by ethnic group. Because helping the family did not relate to less studying behavior, study time and study days could not explain the negative association between assistance days and achievement among adolescents with Mexican and Chinese backgrounds.

Similarly, the last two columns of Table 4 suggest that the negative implications of family assistance for achievement among those with Mexican and Chinese backgrounds were not due to learning and attendance problems. Assistance days were not associated with greater learning and attendance problems among adolescents from Mexican and Chinese backgrounds. Instead, the only significantly positive association was observed between assistance days and 
Table 4 Hierarchical linear modeling predicting studying and school problems by family assistance days

\begin{tabular}{|c|c|c|c|c|}
\hline & $\begin{array}{l}\text { Study time } \\
b \text { (SE) }\end{array}$ & $\begin{array}{l}\text { Study days } \\
b \text { (SE) }\end{array}$ & $\begin{array}{l}\text { Learning problems } \\
b \text { (SE) }\end{array}$ & $\begin{array}{l}\text { Attendance } \\
b \text { (SE) }\end{array}$ \\
\hline Intercept & $.88(.13)^{* * *}$ & $.52(.03) * * *$ & $2.86(.54) * * *$ & $2.19(.58) * * *$ \\
\hline Gender & $.45(.12)^{* * *}$ & $-.07(.04)$ & $1.69(.50)^{* * *}$ & $1.01(.59)$ \\
\hline Mexican & $-.55(.15)^{* * *}$ & $-.20(.05)^{* * *}$ & $-.83(.77)$ & $1.79(.87)^{*}$ \\
\hline Chinese & $.14(.15)$ & $-.05(.04)$ & $-.28(.58)$ & $1.05(.66)$ \\
\hline Assist days & $.18(.17)$ & $.14(.05)^{* *}$ & $1.30(.77)$ & $2.04(.88)^{*}$ \\
\hline Gender & $-.25(.15)$ & $.07(.07)$ & $-1.93(.67)^{* *}$ & $-.65(.78)$ \\
\hline Mexican & $.16(.19)$ & $.09(.06)$ & $1.90(1.02)$ & $-1.45(1.17)$ \\
\hline Chinese & $.09(.19)$ & $-.07(.04)$ & $.06(.82)$ & $-2.90(.97)^{* *}$ \\
\hline Standard deviation of assistance estimate & .13 & $.11^{*}$ & 1.09 & .70 \\
\hline
\end{tabular}

Note: Study time represents youths' average time spend studying each year. Study days represent youths' proportion of days studying each year. Learning problems refer to school problems such as not understanding something taught in class or doing poorly on a test or quiz. Attendance problems refer to school problems such as being late for class or skipping school. Assistance days represents the proportion of days adolescents helped their family by engaging in one or more of the eight family assistance behaviors. Gender was coded males $=0$, females $=1$. Ethnicity was dummy coded with adolescents from European backgrounds serving as the reference group. $* p<.05, * * p<.01$, *** $p<.001$

attendance problems for students from European backgrounds, who did not evidence the original link between more family assistance days and lower GPA.

\section{Discussion}

Adolescents from Latin American and Asian backgrounds place a strong emphasis on family obligation and assistance and results from this study suggest that assisting the family may impact their academic achievement more so than their peers from European backgrounds. Whereas changes in assistance time across the high school years did not relate to changes in academic achievement for any students, increases in assistance days over the years was associated with poorer achievement for adolescents from Mexican and Chinese backgrounds. These ethnic differences were not accounted for by generational status, socioeconomic background, or family composition variables. Furthermore, the association between family assistance and academic achievement could not be explained by school related problems or a reduction in adolescents' study time.

Results from this study suggest that it is the act of helping on more days, rather than the amount of time helping that may be associated with poorer achievement. These findings suggest that family assistance as a chronic and frequent activity may interfere with adolescents' lives. Assisting the family on most days of the week suggests that it is a chronic behavior and adolescents who help every day may find it to be more demanding than those who help for the same number of hours but on fewer days. Further, the family context in which an adolescent helps every day is likely different than in a family in which adolescents don't help every day. Helping on most days may suggest that the adolescents' assistance is a daily necessity, perhaps due to economic or social stresses in the household. Indeed, children in families experiencing economic difficulties are more likely to assume responsibilities and be involved in household chores compared to their better-off peers (Burton 2007; Elder 1974). Further, taking on extensive responsibilities within difficult family contexts may lead to compromised academic performance and lower achievement (Burton 2007). Together, these studies suggest that assistance as a frequent and chronic activity may be too difficult for some teenagers to manage.

Adolescents from Mexican and Chinese backgrounds tend to spend more time helping their family than their European peers, and it is possible that increases in the proportion of days helping the family were more consequential for Mexican and Chinese youth because these adolescents were already at a high level of assistance. In addition, assisting the family may lead to poorer achievement for adolescents from Mexican and Chinese backgrounds because there are qualitative differences in the family assistance behaviors between the different ethnic groups. We are able to measure the quantitative aspects of family assistance and have found that youth from Mexican and Chinese backgrounds help more than their peers from European backgrounds. However, we know little about the sources of and quality of their family assistance behaviors. For example, sibling care or meal preparation may be more intensive and consequential in Mexican and Chinese families. The same family assistance activities, therefore, may be harder to manage for some adolescents in different family contexts. Understanding the family environments, the context in which assistance takes place, and the quality of the family assistance may help to 
clarify why helping the family leads to poorer achievement for youth from Mexican and Chinese backgrounds.

Adolescents from Mexican and Chinese backgrounds are more likely to come from immigrant families, and there may be stresses associated with being an immigrant that make it harder to manage their family obligations and school work. Immigrant youth do take on more household responsibilities (Fuligni and Pederson 2002; Fuligni et al. 1999; Hardway and Fuligni 2006) and often express feelings of stress and conflict deriving from their family obligations and school work (Suarez-Orozco and SuarezOrozco 1995). However, we did not find that generational differences explained why Mexican and Chinese youth who help on more days receive lower grades, and there were not differences between immigrant and nonimmigrant youth in the association between family assistance and achievement. Therefore, immigrant and latter generation youth are similarly affected by their family obligations. Assisting their family may be more consequential for adolescents from immigrant families, but generational differences may not be detectable to us in the current study. Future work should tap immigrant stress more directly by examining levels of acculturation, family support, feelings of conflict, language barriers, and other possible sources of strain for immigrant families. By examining the more circumstantial and detailed aspects of immigrant families' environments, we may be able to understand how family assistance impacts their lives.

In addition, adolescents from Mexican and Chinese backgrounds are more likely to come from families whose parents have less education and are in lower status occupations. Further, these adolescents are more likely to live with their grandparents and to have more siblings living in residence. Family assistance within economically disadvantaged households or within difficult family environments may be more stressful and detract from school work (Burton 2007). Nonetheless, parental education and occupation, number of siblings, living with grandparents, and having dual parents in residence did not explain why assisting the family is more consequential for adolescents from Mexican and Chinese backgrounds. Thus, there are likely other differences between the family environments of these youth that we were not able to pick up on. Future studies should include a more dynamic measure of economic strain. We do not have information about the families' economic needs, whether the adolescents' help is imperative for the families' survival, or why the adolescents are helping. Immigrant families have unique financial situations in which they often send money to family members in their home country (Fuligni and Yoshikawa 2003). Our measure of socioeconomic status does not tap these sources of financial stress, and thus may not be sensitive to ethnic or generational differences.
Finally, we found that school problems and studying do not explain why assisting the family impedes achievement for some youth. Contrary to the expectations of theorists (e.g., Chase 1999), adolescents did not spend less time studying on years in which they helped their family more. Rather, adolescents spent more days studying on years in which they helped their family more. This is consistent with the findings of Hardway and Fuligni (2006) who found that youth who spend more time helping their family also spend more time studying. Given the positive association between family assistance and studying, it is unclear why assisting the family relates to poorer achievement for some youth. Perhaps the high levels of assistance plus the high levels of studying are too much for some adolescents. Indeed, youth from Mexican and Chinese backgrounds help their families significantly more than their peers from European backgrounds, and trying hard and doing well in school is often an important aspect of their family obligations (Fuligni 2001). Yet, they often feel torn between helping their family and doing their school work (Suarez-Orozco and Suarez-Orozco 1995). Because youth who assist more also study more, they are likely doing both activities together while at home. For example, youth may assist their family during the evening and then stay up late in order to complete their school work, or they may multitask and try to study while helping their family. Thus, they may not study less, but the quality of their studying may be affected as a result of their family assistance. Future work should tap the situational and daily context in which family assistance is taking place. A study that samples real life situations and events as they occur can examine what adolescents are doing in the moment, whether they are multitasking, who they are with, and the environment in which they are studying and/or assisting their family. Such a study could help clarify whether the quality of adolescents' studying is affected by their family assistance behaviors.

Youth from Mexican and Chinese backgrounds often feel it is an obligation to their family to study hard and do well in school (Chao and Tseng 2002; Fuligni 2001; Hardway and Fuligni 2006). These adolescents have a strong sense of family obligation which has been associated with increased academic motivation (Fuligni 2001). Yet, their actual family assistance behaviors may impede their academic achievement, making the implications for policymakers complicated. Family obligation is an important cultural value for adolescents from Latin American and Asian backgrounds. It provides them a sense of academic motivation, and assisting their family gives them a sense of role fulfillment and happiness (Fuligni 2001; Orellana 2001; Suarez-Orozco and Suarez-Orozco 1995; Telzer and Fuligni 2009). Thus, interventions should not aim to decrease these youth's family assistance behaviors. 
Rather, teachers, schools, and families should help Mexican and Chinese youth find ways to manage their time more effectively so that assisting their family doesn't interfere with their school work. Recent intervention work shows that culturally sensitive school-based programs that combine traditional familistic values are effective in engaging and motivating Mexican youth and promoting their academic success (e.g., Dillman Carpentier et al. 2007; Martinez and Eddy 2005). Similarly, schools could be made more aware of the unique challenges facing these students and consider ways to allow for more flexibility in work load and deadlines when the need to assist the family arises. In the absence of larger social and economic programs that work to alleviate some of the economic hardships of immigrant and ethnic minority families, such family- and school-based interventions may be the most effective way to assist the students and their families.

Several limitations in the current study should be acknowledged. First, there may be sample biases since the participation rate was around $60 \%$ each year. Those who did not participate may be adolescents who come from more difficult home environments, such as those characterized by economic difficulties, parental illness, or parents who are absent due to separation. Thus, we may be missing an important subgroup of adolescents, those who may experience the most stresses associated with their family assistance. In addition, our measure of socioeconomic status does not tap economic strain and youths' reports of their parents' education and occupation may not accurately portray their family's economic need. Thus, it is unclear from the current study how economic difficulties may affect the association between family assistance and academic achievement. Future work should measure economic need more directly by asking parents to report on their economic background. Additionally, our measure of family assistance does not capture qualitative differences in family assistance, such as variations in task difficulty and intensity, which may elucidate why helping the family may be more consequential for some adolescents. Finally, it is important to acknowledge that there are differences in social, ethnic, and socioeconomic distributions between the three schools sampled, such as CalWorks distributions, free and reduced meal differences, and ethnic group representation. It is possible that characteristics about the school and the education provided may be related to academic achievement in addition to the level of family assistance provided by the adolescents. In particular, because ethnicity and school are highly confounded, the ethnic differences in the association between family assistance and academic achievement could be due to the schools the students are attending and not just due to ethnicity. However, we cannot separate out these two effects because we sampled only three schools in the study, which is not enough to be able to make any strong conclusions about school effects.

In conclusion, a growing body of research shows that adolescents from Latin American and Asian backgrounds are some of the most academically motivated students in the United States (Fuligni 1997); yet, their achievement levels do not always match their motivational aspirations. One major source of their motivation derives from their values of family obligation, their sense to support, respect, and help their family (Fuligni 2001; Tseng 2004). Nevertheless, we found that the school achievement of students from Mexican and Chinese backgrounds may suffer when family assistance is a chronic activity that occurs across many days of the week. Additional research should focus on the sources and nature of this high frequency of assistance in order to better assist these students to succeed in high school at levels equal to their motivation and aspirations.

Acknowledgments Support for this study was provided by a grant from the Russell Sage Foundation to Andrew J. Fuligni. Preparation of this manuscript was supported in part by the National Science Foundation Graduate Fellowship. We thank the participating students and schools as well as Christina Hardway, Melissa Witkow, and Chadryn Agpalo for their assistance with the study design and data collection.

Open Access This article is distributed under the terms of the Creative Commons Attribution Noncommercial License which permits any noncommercial use, distribution, and reproduction in any medium, provided the original author(s) and source are credited.

\section{References}

Birman, D. (2006). Measurement of the "acculturation gap" in immigrant families and implications for parent-child relationships. In M. H. Bornstein \& L. R. Cote (Eds.), Acculturation and parent-child relationships: Measurement and development (pp. 113-134). Mahwah, NJ: Erlbaum and Associates.

Bolger, N., Davis, A., \& Rafaeli, E. (2003). Diary methods: Capturing life as it is lived. Annual Review of Psychology, 54, 579-616. doi:10.1146/annurev.psych.54.101601.145030.

Bryk, A. S., \& Raudenbusch, S. W. (1992). Hierarchical linear models: Applications and data analysis methods. Newbury Park, CA: Sage.

Buriel, R., Perez, W., de Ment, T. L., Chavez, D. V., \& Moran, V. R. (1998). The relationship of language brokering to academic performance biculturalsm, and self-efficacy among Latino adolescents. Hispanic Journal of Behavioral Sciences, 20(3), 283-297. doi:10.1177/07399863980203001.

Burton, L. M. (2007). Childhood adultification in economically disadvantaged families: A conceptual model. Family Relations, 56(4), 329-345. doi:10.1111/j.1741-3729.2007.00463.x.

California Department of Education. (2006). School summary data. Retrieved January 27, 2006, from http://dq.cde.ca.gov/dataquest.

Chao, R., \& Tseng, V. (2002). Parenting of asians. In M. H. Bornstein (Ed.), Handbook of parenting: Social conditions and applied parenting (Vol. 4, pp. 59-93). Mahwah, NJ: Erlbaum Associates.

Chase, N. D. (1999). Parentification: An overview of theory, research, and societal issues. In N. D. Chase (Ed.), Burdened children: 
Theory, research, and treatment of parentification (pp. 3-34). Thousand Oaks, CA: Sage.

Crouter, A. C., Head, M. R., Bumpus, M. F., \& McHale, S. M. (2001). Household chores: Under what conditions do mothers lean on daighters. In A. J. Fuligni (Ed.), Family obligation and assistance during adolescence: Contextual variations and developmental implications, (new directions in child and adolescent development monograph) (pp. 23-41). San Francisco: Jossey-Bass Inc.

Dillman Carpentier, F. R., Maurico, A. M., Gonzales, N. A., Millsap, R. E., Meza, C. M., Dumka, L. E., et al. (2007). Engaging Mexican origin families in a school-based preventive intervention. The Journal of Primary Prevention, 28(6), 521-546. doi: 10.1007/s10935-007-0110-z.

Elder, G. H., Jr. (1974). Children of the great depression: Social change in life experience. Chicago: University of Chicago Press.

Flook, L., \& Fuligni, A. J. (2008). Family and school spillover in adolescents' daily lives. Child Development, 79(3), 776-787. doi:10.1111/j.1467-8624.2008.01157.x.

Fuligni, A. J. (1997). The academic achievement of adolescents from immigrant families: The roles of family background, attitudes, and behavior. Child Development, 68, 261-273.

Fuligni, A. J. (1998). Parental authority, adolescent autonomy, and parent-adolescent relationships: A study of adolescents from Mexican, Chinese, Filipino, and European backgrounds. Developmental Psychology, 34, 782-792. doi:10.1037/0012-1649.34. 4.782.

Fuligni, A. J. (2001). Family obligation and the academic motivation of adolescents from Asian, Latin American, and European backgrounds. In A. J. Fuligni (Ed.), Family obligation and assistance during adolescence: Contextual variations and developmental implications, (new directions in child and adolescent development monograph) (pp. 61-76). San Francisco: Jossey-Bass Inc.

Fuligni, A. J., \& Pederson, S. (2002). Family obligation and the transition to young adulthood. Developmental Psychology, 38, 856-868. doi:10.1037/0012-1649.38.5.856.

Fuligni, A. J., Tseng, V., \& Lam, M. (1999). Attitudes toward family obligations among American adolescents from Asian, Latin American, and European backgrounds. Child Development, 73, 302-314. doi:10.1111/1467-8624.00407.

Fuligni, A. J., \& Witkow, M. (2004). The postsecondary educational progress of youth from immigrant families. Journal of Research on Adolescence, 14(2), 159-183. doi:10.1111/j.1532-7795.2004. 01402002.x.

Fuligni, A. J., Yip, T., \& Tseng, V. (2002). The impact of family obligation on the daily activities and psychological well-being of Chinese American adolescents. Child Development, 73, 302314. doi:10.1111/1467-8624.00407.

Fuligni, A. J., \& Yoshikawa, H. (2003). Socioeconomic resources, parenting, and child development among immigrant families.
In M. H. Bornstein \& R. H. Bradley (Eds.), Socioeconmic status, parenting, and child development. Mahwah, NJ: Erlbaum Associates.

Hardway, C., \& Fuligni, A. J. (2006). Dimensions of family connectedness among adolescents with Chinese, Mexican, and European backgrounds. Developmental Psychology, 42, 12461258. doi:10.1037/0012-1649.42.6.1246.

Martinez, C. R., \& Eddy, J. M. (2005). Effects of culturally adapted parent management training on Latino youth behavioral health outcomes. Journal of Counseling and Clinical Psychology, 73, 841-851. doi:10.1037/0022-006X.73.5.841.

Orellana, M. F. (2001). The work kids do: Mexican and Central American immigrant children's contribution to households and school in California. Harvard Educational Review, 71, 366-389.

Orellana, M. F., Dorner, L., \& Pulido, L. (2003). Accessing assets: Immigrant youth's work as family translators or "para-phrasers". Social Problems, 50(4), 505-524. doi:10.1525/sp.2003. 50.4.505.

Suarez-Orozco, C., \& Suarez-Orozco, M. (1995). Transformations: Immigration, family life, and achievement motivation among Latino adolescents. Stanford: Stanford University Press.

Suarez-Orozco, M. (1991). Immigrant adaptation to schooling: A Hispanic case. In J. U. Ogbu \& M. Gibson (Eds.), Minority status and schooling: A comparitive study of immigrant and involuntary minorities (pp. 37-60). New York: Garland.

Telzer, E. H., \& Fuligni, A. J. (2009). Daily family assistance and the psychological well being of adolescents from Latin American, Asian, and European backgrounds. Developmental Psychology (in press).

Tseng, V. (2004). Family interdependence and academic adjustment in college: Youth from immigrant and U.S.-born families. Child Development, 75(3), 966-983. doi:10.1111/j.1467-8624.2004.007 17.x.

Valenzuela, A. (1998). Gender roles and settlement activities among children and their immigrant families. The American Behavioral Scientist, 42, 702-742.

\section{Author Biographies}

Eva H. Telzer is a graduate student in Psychology at the University of California, Los Angeles. Her research focuses on family relationships and well-being among ethnically diverse adolescents.

Andrew J. Fuligni is Professor of Psychology and Psychiatry at the University of California, Los Angeles. Dr. Fuligni's research focuses on family relationships and adolescent development among culturally and ethnically diverse populations. 